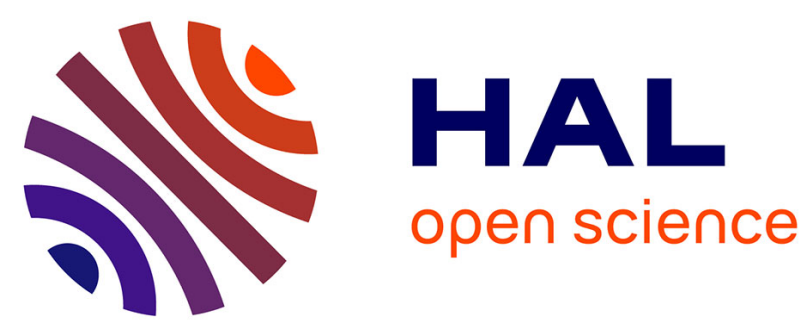

\title{
Core modal spatial-structuring in inhibited-coupling hollow-core fibers
}

Jonas Osorio, Matthieu Chafer, Benoît Debord, Fabio Giovanardi, Martin

Cordier, Martin Maurel, Frédéric Delahaye, Foued Amrani, Luca Vincetti, Frédéric Gérôme, et al.

\section{To cite this version:}

Jonas Osorio, Matthieu Chafer, Benoît Debord, Fabio Giovanardi, Martin Cordier, et al.. Core modal spatial-structuring in inhibited-coupling hollow-core fibers. Conference on Laser and Electro-Optics /Europe (CLEO/Europe-EQEC 2019), Jun 2019, OSA, Jun 2019, Munich, Germany. Paper CE-7.2. hal-02330803

\section{HAL Id: hal-02330803 https://hal.science/hal-02330803}

Submitted on 23 Nov 2020

HAL is a multi-disciplinary open access archive for the deposit and dissemination of scientific research documents, whether they are published or not. The documents may come from teaching and research institutions in France or abroad, or from public or private research centers.
L'archive ouverte pluridisciplinaire HAL, est destinée au dépôt et à la diffusion de documents scientifiques de niveau recherche, publiés ou non, émanant des établissements d'enseignement et de recherche français ou étrangers, des laboratoires publics ou privés. 


\title{
Core modal spatial-structuring in inhibited-coupling hollow-core fibers
}

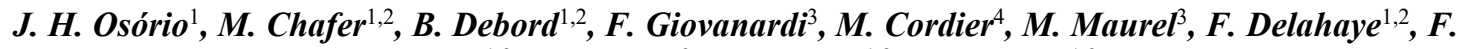

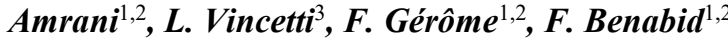 \\ 1. GPPMM Group, XLIM Research Institute, CNRS UMR 7252, University of Limoges, Limoges, France. 2. GLOphotonics S.A.S., 1 avenue \\ d'Ester, Ester Technopôle, Limoges, France. 3. Department of Engineering "Enzo Ferrari", University of Modena and Reggio Emilia, \\ Modena, Italy. 4. Laboratoire de Traitement et Communication de l'Information, Télécom ParisTech, Université Paris-Saclay, Paris, \\ France
}

A profound knowledge of the cladding mode properties and their interaction with the core modes is decisive for successfully designing inhibited-coupling (IC) guiding hollow-core photonic-crystal fibers (HC-PCFs). In IC fibers, the core and cladding modes coupling is robustly minimized due to a strong mismatch between their transverse phases and a small overlap between their fields. In the latest years, great attention has been given to IC fibers, especially since the introduction of the hypocycloid core contour concept [3], which entailed a dramatic loss reduction and preceded the development of single-ring tubular-lattice (SR-TL) HC-PCFs [4]. The interest on SR-TL HC-PCFs is due to their noteworthy properties such as geometric simplicity and the absence of connecting nodes in the fiber cladding, which favors IC guidance. Efforts on SR-TL HC-PCFs development entailed the accomplishment of ultra-low loss and broad transmission bandwidth [5]. Here, we show that the alteration of the lattice-tubes azimuthal position in SR-TL HC-PCFs causes modifications in the mode loss hierarchy and can be used to select the propagation of specific higher order modes (HOMs). It can be done by conveniently enlarging the spacing between the cladding tubes and by providing additional leakage to the fundamental mode while keeping low impact in the confinement loss (CL) of specific HOMs. It allows obtaining uncommon intensity profiles and polarization properties at the fiber output allowing it to act as a mode shaper.

Fig. 1a shows three fiber designs (FD) and their simulated CL spectra for the $\mathrm{LP}_{01}$ and selected HOMs. FD\#1 is a 10-tubes lattice fiber and has the $\mathrm{LP}_{01}$ mode as the lowest loss one $(3.6 \mathrm{~dB} / \mathrm{km}$ at $1000 \mathrm{~nm})$. In FD\#2, by creating two larger gaps between the lattice tubes $\left(\right.$ at $\left.180^{\circ}\right)$, the $\mathrm{LP}_{01}$ mode $\mathrm{CL}$ increases by two orders of magnitude while keeping low impact on the $\mathrm{LP}_{11, \mathrm{a}}$ mode $\mathrm{CL}$ (modes profiles in Fig. 1a). It causes the latter to be the lowest loss one. In FD\#3, the cladding structure has four larger gaps (at $90^{\circ}$ ) and favors $\mathrm{LP}_{21}$ mode propagation. Poynting vector plots $\left(\mathrm{p}_{\mathrm{r}}\right)$ in Fig. 1a maps the mode leaking channels for the different modes in the different FDs. Two fibers (F\#1 and F\#2) were fabricated and the losses of selected HOM were measured (Fig. 1b). The losses were measured for the situations in which $\mathrm{LP}_{11}$ - and $\mathrm{LP}_{21}$-like profiles were seen at the fiber output. Finally, mode transformations in F\#1 and F\#2 were tested. Fig. 1c presents the uncommon fiber output profiles obtained for different input polarization angles. The unusual profiles observed in Fig. 1c arises from mode superpositions in F\#1 and F\#2 and are achievable by convenient light coupling. In particular, the lobes in the $\mathrm{LP}_{11}$-like profile in $\mathrm{F} \# 1$ have orthogonal polarization states, which is remarkable and very particular. We believe this novel concept will find applications in atom optics, atom-surface physics, sensing and nonlinear optics. Further details can be found in [6].

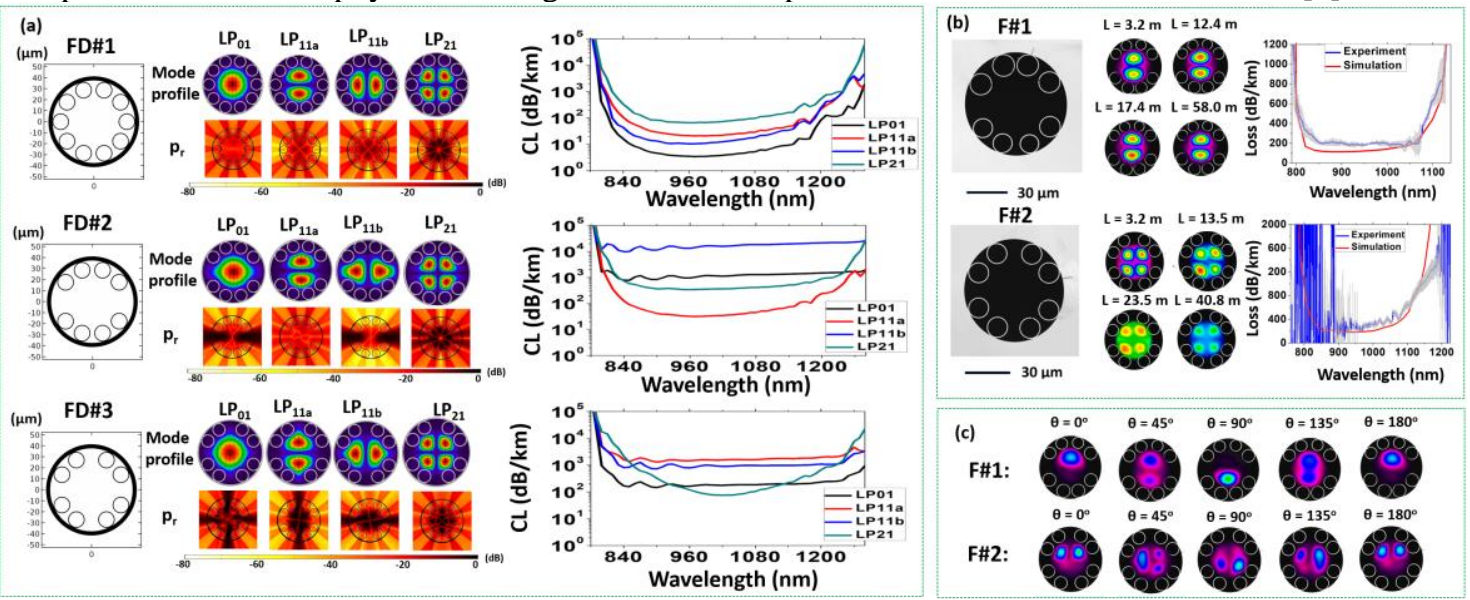

Fig. 1 (a) Fiber designs, mode profiles, Poynting vector map ( $\mathrm{p}_{\mathrm{r}}$ ) and simulated CL. (b) Fabricated fibers, output nearfield profiles and loss measurement of HOMs. (c) F\#1 and F\#2 output for different input polarization angles.

This research was funded by PIA $4 F$ and Région Nouvelle-Aquitaine projects.

\section{References}

[1] T. A. Birks et al. "Full 2-D photonic bandgaps in silica/air structures," Electronics Letters 31, 1941-1943 (1995).

[2] F. Couny et al. "Generation and photonic guidance of multi-octave optical frequency combs," Science 318, 1118-1121 (2007)

[3] Y. Wang et al. "Low loss broadband transmission in optimized core-shape Kagome hollow core PCF. In CLEO (2010), paper CPDB4.

[4] A. D. Pryamikov et al. "Demonstration of a waveguide regime for a silica hollow-core microstructured optical fiber with a

negative curvature of the core boundary in the spectral region > $3.5 \mu \mathrm{m}$," Optics Express 19, 1441-1448 (2011).

[5] B. Debord et al. "Ultralow transmission loss in inhibited-coupling guiding hollow fibers," Optica 4, 209-217 (2017).

[6] J. H. Osório et al. "Tailoring modal properties of inhibited-coupling guiding fibers by cladding modification" Scientific Reports (accepted, 2019). 